\title{
Programas educacionais para a pequena infância na Itália*
}

\author{
Tullia Musatti \\ Instituto de Ciências e Tecnologias do Conhecimento. Conselho Nacional de Pesquisas, Roma, Itália
}

Tradução: Giovanni Semeraro

Universidade Federal Fluminense, Faculdade de Educação

Revisão Técnica: Ana Lúcia Goulart de Faria

Universidade Estadual de Campinas, Faculdade de Educação

\section{Introdução}

Na segunda metade do século passado, na Itália, ocorreram profundas e amplas transformações no contexto de um conjunto de fenômenos sociais estritamente vinculados ao problema do cuidado e da educação das crianças pequenas. A estrutura da família passou a sofrer fortes transformações. Entre as mais importantes, encontramos o aumento significativo das famílias nucleares e principalmente a drástica redução da natalidade, que chegou a parar nos últimos anos, fixando-se no nível de crescimento zero da população, cujas causas e sintomas são ao mesmo tempo o casamento adiado e a procriação tardia. Esses fenômenos contribuíram para determinar também uma condição diferente para a criança pequena no interior da família. A maioria das crianças abaixo dos 3 anos são filhos únicos e, quando ganham um irmão ou uma

* Trabalho apresentado no GT Educação da Criança de 0 a 6 anos, durante a $25^{\text {a }}$ Reunião Anual da ANPEd, realizada em Caxambu, MG, 29 de setembro a 2 de outubro de 2002. irmã, estão já na idade escolar (Musatti, 1992). Pelas mesmas razões a criança pequena, muitas vezes, é também a única presença infantil no interior da grande família, de forma que a atenção de muitos adultos se concentra nela.

Também, a condição das mulheres na sociedade mudou profundamente. A escolaridade das mulheres tem aumentado expressivamente ao longo das últimas duas gerações, superando a dos homens nas correspondentes faixas de idade, de maneira que a presença das mulheres no mercado de trabalho expandiu-se fortemente, seja no número de empregos, seja como demanda e qualidade dos postos de trabalho.

$\mathrm{O}$ acesso das mulheres ao mercado de trabalho explica-se pela escolaridade, nitidamente mais relevante que a dos homens; atualmente, trata-se de um importante e característico componente da empregabilidade das mulheres. Embora as grandes diferenças históricas do mercado de trabalho entre a região Centro-Norte e a do Sul do país venham a se refletir na distribuição do emprego feminino, a pressão para o trabalho fora de casa é forte no país inteiro. Observa-se uma importante participação na força 
de trabalho também das mães das crianças abaixo dos 3 anos: $41 \%$ encontram-se empregadas, porcentagem que corresponde à média dos países europeus. Assim, gerar filhos traz um efeito mais específico no trabalho das mulheres do que no dos homens. De fato, a porcentagem das mães trabalhadoras com crianças abaixo dos 3 anos (52\%) é muito menor que a das mulheres com idade entre 25 e 44 anos (período que corresponde em geral à idade de procriação na Itália), enquanto entre os homens encontramos uma porcentagem mais baixa de não-trabalhadores $(10 \%)$ entre os pais de crianças pequenas do que entre todos os homens em idade entre 25 e 44 anos (26\%). Enfim, parece que os homens se tornam pais quando estão já inseridos no mercado de trabalho, enquanto a maternidade afasta mais freqüentemente as mulheres do trabalho, embora não tão freqüentemente como se poderia pensar.

Essas mudanças na condição social feminina vieram acompanhadas de importantes mudanças também nos comportamentos, hábitos e atitudes das mulheres em suas relações no interior da família. Entrou em discussão a função da mulher na administração da casa e com o cuidados dos filhos, enquanto se difunde lentamente a idéia de uma partilha da criação entre os dois parceiros. No lugar da família extensa surgiu a vertical, e as relações no seu interior se tornaram principalmente relações entre gerações, implicando novas e mais reduzidas formas de intercâmbio.

Todos esses processos convergem para o desenho de uma nova condição de maternidade/paternidade. Em geral, veio a se criar uma realidade de isolamento material e psicológico no casal com crianças pequenas, mas também uma consciência diferente em relação ao cuidado e à educação das crianças e das suas diversas necessidades de apoio. Assim, cresceu e se ampliou para diversas tipologias de famílias a necessidade de apoio material no cuidado das crianças, o que se expressou na demanda dos programas educacionais. Ao mesmo tempo, porém, vieram aumentando e se diferenciando também as necessidades psicológicas dos pais. Trata-se de novas necessidades relativas à educação das crianças, como por exemplo o desejo que elas tenham experiências precoces com outras crianças. Mas, trata-se, também, de novas necessidades de apoio emocional e psicológico à experiência dos pais.

Diante dessa situação, qual é a oferta dos programas educativos para a infância? Como responder à quantidade e qualidade das demandas das famílias?

O sistema educativo para a infância está dividido nitidamente em duas partes conforme a idade das crianças: as creches para as crianças abaixo dos 3 anos e as escolas de infância para crianças entre 3 e 6 anos (a partir de 6 anos começa a escola obrigatória). $\mathrm{O}$ financiamento e a gestão da grande maioria das creches e das escolas de infância são públicos.

\section{As crianças entre 3 e 6 anos: a escola da infância}

Mais de $90 \%$ das crianças entre 3 e 6 anos freqüentam uma escola de infância. Existem ainda préescolas que funcionam apenas na parte da manhã, mas a grande maioria acolhe as crianças das $8 \mathrm{~h}-8: 30 \mathrm{~h}$ da manhã até 16h-16:30h da tarde e serve o almoço ao meio dia. A maioria dessas escolas são públicas: mais de 50\% de responsabilidade do Estado e 13\% dos municípios que começaram a criá-las antes da iniciativa do Estado (1968) e continuaram depois a sustentá-las, realizando experiências de elevada qualidade, como as escolas dos municípios de Pistóia e de Reggio Emilia. A iniciativa dos municípios é muito decisiva particularmente nas grandes cidades, como por exemplo em Roma, onde $60 \%$ das crianças, entre 3 e 6 anos, freqüentam uma pré-escola municipal. As escolas da infância públicas são gratuitas e os pais pagam apenas uma contribuição para as refeições. Um quarto das crianças encontram-se em escolas particulares administradas, em geral, por religiosos. Em 2000, uma lei nacional reconheceu a paridade entre as diversas escolas de infância (ou seja, o direito a receber um financiamento estatal) desde que respeitem um certo nível de qualidade. Ainda no ano 2000, estava sendo aprovada uma lei de reforma de todo o sistema escolar, com a qual se reconhecia que a escola da infância é o pri- 
meiro segmento do percurso formativo e se estabelecia que é um direito de todas as crianças entre 3 e 6 anos e que, portanto, o Estado deveria garantir a sua difusão também nas cidades e vilarejos (particularmente do Sul) onde não existia. Essa lei não se concretizou por motivos de mudanças políticas e o governo atual está formulando uma outra lei pela qual se propõe a antecipar o ingresso na escola de infância aos 2 anos e meio e o da escola elementar obrigatória aos 5 anos e meio. Essa proposta encontra muita resistência, seja na associação dos municípios italianos, seja nas associações profissionais e sindicais dos professores.

Mesmo havendo grandes diferenças entre as escolas de infância italianas, a maioria tem em comum algumas concepções educativas: a conotação da préescola como ambiente educativo, uma escassa ênfase na aprendizagem precoce da leitura, da escrita ou do cálculo, a existência de formas de participação dos pais na vida e na gestão da escola. Para a escola da infância do Estado vigoram ainda hoje as novas orientações, elaboradas em 1991 por uma comissão de docentes universitários após uma ampla consulta às préescolas e às associações de profissionais e de pais.

\section{A creche e os outros programas para as crianças abaixo dos 3 anos}

Em relação às crianças abaixo dos 3 anos a situação é muito diferente. $\mathrm{O}$ cuidado extradoméstico de crianças abaixo dos 3 anos chega a ser um fenômeno quantitativamente relevante no decorrer dos anos 1970. Em 1971, em virtude de batalhas e pressões dos sindicatos e dos movimentos feministas, uma lei nacional instituía creches para todo o território nacional. Até hoje, a creche é o único tipo de serviço de cuidado para as crianças abaixo dos 3 anos na Itália, embora de forma experimental existam algumas creches domiciliares. A creche recebe as crianças desde 3 meses de idade até 3 anos, de segunda a sexta feira, durante o período de trabalho: em geral, permanecendo aberta das 7h-7:30h da manhã até 17h-18h da tarde, embora as crianças permaneçam lá menos tempo, isto é, das 8h-8:30h até 16h-16:30h.
A lei de 1971 deixava a programação, a construção, a regulamentação e a gestão das creches para as administrações municipais e regionais. Isso promoveu uma importante expansão quantitativa, embora não homogênea, pelo fato de depender de diversas políticas locais. Em sua maioria, as creches existentes foram instaladas entre 1975 e 1985 . Nos anos seguintes, a crise econômica do país, o corte de financiamentos nacionais para a construção e significativas vinculações financeiras e gerenciais impostas às administrações locais, levaram a paralisar a expansão das creches. Mesmo assim, salvo casos raros, em cidades muito pequenas, é relevante o fato de que em nenhum lugar houve creches fechadas, como muitos previam; pelo contrário, quase por toda parte foi registrado um crescimento lento mas contínuo do número das creches.

Atualmente, apenas 7\% das crianças abaixo dos 3 anos freqüentam uma creche, mas esse percentual varia de uma região para outra (desde $18 \%$ na região Emilia-Romagna até menos de $1 \%$ na região Campania). As creches estão mais concentradas no Norte e no Centro do país e são mais numerosas nas cidades de dimensões médias onde é possível encontrar até mais de $30 \%$ das crianças. A grande maioria das creches é administrada pelos governos locais com financiamentos públicos, enquanto os pais dão contribuições que variam conforme a renda e podem ser muito diferentes de uma cidade para outra. Uma pesquisa recente realizada pelo Centro de Documentação Nacional para a Infância e Adolescência (2002) tem constatado também uma oferta de creches particulares (muitas vezes não regularizadas) que chega a representar $20 \%$ da oferta atual das creches na Itália. $\mathrm{O}$ aumento constante de creches públicas e privadas depende da pressão das famílias, cujas solicitações ficam cada vez mais indeferidas, não obstante a concomitante diminuição demográfica. É importante sublinhar que o aumento da demanda de creches está fortemente relacionada à oferta: nas cidades e regiões onde há mais creches, há também mais procura pelas famílias.

O surgimento da creche na Itália marcou profundamente a experiência de atendimento às crianças 
pequenas. Particularmente dois pontos serão destacados evidenciando aspectos característicos da experiência italiana.

A creche na Itália foi instituída como bem público administrado pelos governos locais, com um grande investimento financeiro direto. Assim, embora a creche receba prioritariamente os filhos das mulheres trabalhadoras, acabou de fato sendo entendida como um programa disponível para toda a comunidade, de modo que a sua experiência tem sido fortemente vinculada à cultura da comunidade local. A gestão social da creche definida por lei em quase todas as cidades significava a participação das famílias diretamente usuárias na gestão de alguns de seus aspectos de funcionamento, mas, muitas vezes, observava-se o envolvimento de outros moradores da comunidade local.

A instituição da creche ocorreu pela pressão política e sindical, cuja demanda vinha acompanhada pela afirmação do valor do trabalho extradoméstico das mulheres e, por extensão, pelo valor da educação extradoméstica precoce. Tudo isso teve sua influência nas posições ideológicas dos atores em relação ao mundo da creche. Inicialmente os educadores entenderam a sua prática profissional como uma missão de grande importância cultural e política. Ao levar a sério o próprio trabalho para além do que poderia representar aos olhos dos usuários, ao longo dos anos, este veio se transformando em incentivo para o desenvolvimento de um profissionalismo específico na educação da primeira infância (Ongari \& Molina, 1995; Ongari, Schadee \& Molina, 1996) e acabou sendo apoiado pela inserção no contrato nacional de trabalho do pagamento de horas dedicadas à formação em serviço. Assim, os governos locais que mais investiram nessas creches tanto política como financeiramente, aos poucos, vieram providenciando um corpo especializado de profissionais de gestão, capacitado também do ponto de vista educacional. Uma pesquisa, recentemente concluída (Musatti, Andreoli, Braga \& Mayer, 1999), mostrou a difusão dessa experiência em quase todos os municípios que possuem rede de creches. Esse tipo de profissional, chamado de coordenador psicopedagógico ou educacional, que está alocado de diferentes formas na administração municipal, desempenha, ao lado de uma variedade de tarefas burocráticas, duas funções específicas, ambas fundamentais. Uma é a de apoiar profissionalmente as práticas educacionais de cada uma das creches na cidade. Portanto, o coordenador garante a qualidade das práticas educativas. A outra função desempenhada pelo coordenador é a de coordenar cada creche inteiramente e, possivelmente, outros programas para a infância na cidade, permitindo assim um intercâmbio de experiências assim como a elaboração de um projeto unitário na cidade. Consequiência disso tem sido o fato de que cada cidade aprofundou alguns temas e práticas em particular, vinculando até as práticas educativas mais singelas a um contexto cultural mais amplo. Em outras palavras, o elo entre prática educativa interna à creche e políticas para a infância da cidade tem sido forte quase em toda a parte.

No começo da experiência da creche havia uma expectativa difusa, embora pouco clara em relação à natureza do seu lugar educativo. Na Itália, portanto, na primeira década de experiência, houve muita pesquisa sobre os aspectos que caracterizam uma creche em relação a outros contextos da vida cotidiana das crianças, para avaliar a qualidade educativa. Em contraste com a tradição psicanalítica, foram estudados os aspectos positivos da experiência precoce de socialização extrafamiliar: a possibilidade de múltiplos vínculos, a importância de um educador de referência para cada criança dentro da creche. Nesses anos, também em sintonia com um interesse pelos temas na comunidade científica internacional, foram produzidos numerosos estudos sobre as interações entre crianças da mesma idade por pesquisadores italianos. O objetivo desses estudos era evidenciar a existência em idade precoce de interações positivas entre crianças da mesma idade, suas implicações cognitivas e emocionais, e a análise dos determinantes dos comportamentos agressivos entre crianças.

Houve uma atenção contínua ao tema das relações entre creche e família. O valor educativo da participação dos pais na vida da creche foi um tema sempre mencionado nas ocasiões de formação em serviço, 
assim como a necessidade de uma comunicação intensa entre a família e o conjunto da creche, não apenas entre cada educador e os pais. Houve também uma atenção particular para os momentos de ruptura na experiência da criança. A adaptação, ou seja, o primeiro período de aproximação das crianças à creche, logo nos primeiros anos de experiência, foi objeto de muita pesquisa, assim como o momento da entrada e da saída diárias. Em relação a essas pesquisas, praticamente cada cidade mais ativa nas políticas educacionais escolheu processos operativos e educativos para a adaptação, muitas vezes expressadas nos regulamentos de gestão. Esse tema até hoje é um dos mais característicos da situação italiana tanto para a pesquisa como para a inovação das práticas educacionais.

\section{A avaliação da qualidade da creche e os problemas abertos}

Nos últimos anos, seguindo uma tendência emergente em muitos outros países e difundida na Itália, também baseado no documento do Child Care Network da Comissão Européia (Balaguer, Mestres \& Penn, 1992), alguns governos locais e regionais realizaram experiências de avaliação da qualidade das creches (Becchi, Bondioli, Centazzo, Cipollone \& Ferrari, 1999; Becchi, Bondioli, Centazzo, Ferrari \& Ghedini, 2000; Benevenuti, Castellani, Cipollone, Falcinelli, Falteri \& Musatti, 2001; Bertin, Catarsi, Faenzi, Fortunati, Frangilli, Galardini, Musatti \& Porchia, 1998; Zanelli, 1998). Nessas experiências foram freqüentemente usados instrumentos originais elaborados especificamente para a situação investigada ou uma versão adaptada da escala ITERS-ECERS. ${ }^{1}$ A especificidade da histó-

${ }^{1}$ ITERS - Escala de Avaliação de Meio Ambiente para Bebês e Crianças em fase pré-escolar, elaborada tendo em vista avaliar programas de grupo para bebês e crianças muito pequenas, em idades que variam do nascimento a 2 anos e meio.

ECERS - Escala de Avaliação de Meio Ambiente para Crianças, para avaliar programas de grupo para crianças no pré-escolar ou no período inicial de escolarização (fase dos “jardins-de-infância"), em idades que variam de 2 anos e meio a 5 anos. ria e da atual gestão das creches da parte dos governos locais fez com que, para além de todas as diferenças, essas experiências apresentassem características comuns:

a) a experiência de avaliação, na quase totalidade dos casos, foi realizada dentro de uma experiência formativa dos educadores e/ou dos coordenadores e acabou se transformando em experiência de auto-avaliação;

b) a experiência tem sido realizada, até hoje, em creches públicas e, orientada à melhoria da qualidade mais do que a uma classificação do nível alcançado;

c) em todos os casos, foram avaliados seja aspectos relativos à qualidade interna de cada creche (organização do ambiente ou diversos elementos interacionais), seja aspectos de gestão relativos ao conjunto do sistema no território como, por exemplo, a resposta do sistema à demanda de creche posta naquela cidade (número de crianças excluídas da creche) ou a quantidade e qualidade da formação em serviço oferecida aos educadores;

d) em muitos casos os resultados da avaliação foram relacionados com instrumentos de avaliação da satisfação dos pais ou da qualidade percebida pelo usuário.

Atualmente, o debate em relação aos processos e objetivos da avaliação das creches se entrelaça com uma discussão mais ampla que gira em torno de algumas questões problemáticas: a insuficiência quantitativa da atual oferta de programas para a infância no país, sua possível diferenciação e o seu significado da educação do conjunto das crianças nas famílias e na sociedade. Questões que tem sido objeto de pesquisa e de práticas inovadoras.

\section{As famílias que usam a creche}

Desde o início dos anos 1980 começaram a surgir perguntas em relação ao status socioeconômico 
das famílias que freqüentavam as creches municipais. Quais famílias, na verdade, utilizavam esse serviço público? Todas as administrações municipais fixaram normas para regular o acesso dos usuários. Salvo os casos sinalizados pelos serviços sociais e as crianças com problemas psicofísicos que geralmente têm prioridade absoluta de acesso, os critérios básicos escolhidos e ainda utilizados até hoje para selecionar as crianças, praticamente, são o trabalho da mãe e a renda familiar. Em todo o caso, apenas um número muito inferior das mães que trabalham têm acesso à creche.

No debate cultural e político, que sempre esteve acalorado em torno da creche, alguns argumentavam que esta acolhia de fato somente os casos de desamparo social ou crianças de famílias em precárias condições socioeconômicas, enquanto outros faziam notar que apenas um tipo restrito de famílias de classe média se dirigia à creche como opção cultural.

Algumas respostas a essas questões vieram das numerosas pesquisas que foram realizadas com as famílias usuárias de creches no decorrer dos anos e em diferentes localidades da Itália do Centro e do Norte (Dipartimento della Funzione Pubblica, 1997; Ingrosso, 1988; Musatti, 1992; Musatti \& Pasquale, 2001; Trifiletti \& Turi, 1983).

Em sua maioria, essas pesquisas foram realizadas por solicitação dos governos locais e com a colaboração dos educadores das creches. Desde a primeira investigação (Trifiletti \& Turi, 1983), promovida pela associação Gruppo Nazionale Nidi di Infanzia, nos municípios mais importantes das regiões Toscana e Úmbria, na área central do país, o envolvimento dos educadores das creches conseguiu maior retorno dos questionários da pesquisa pelas famílias melhor que o esperado, principalmente, onde a qualidade dos centros era melhor e, portanto, das suas relações com as famílias. Ainda que esse primeiro levantamento tivesse o objetivo claro de introduzir instrumentos de coleta das características socioeconômicas das famílias, esse objetivo foi alcançado apenas muito recentemente, e não em todas as cidades, após introduzir nas repartições municipais a informatização para a aceitação das demandas das famílias de acesso à creche. Os levantamentos realizados fornecem dados relativos ao trabalho dos pais das crianças usuárias da creche e sua escolaridade. Alguns dados têm fornecido também as razões da escolha da creche como forma de cuidar da criança e o horário quotidiano da frequiência das crianças.

Duas pesquisas (Musatti, 1992; Musatti \& Pasquale, 2001) apresentam dados das mães de crianças abaixo dos 3 anos que não freqüentam a creche. Ao analisarmos os dados relativos à condição das mães nesses estudos, podemos perceber que, em relação ao trabalho e à profissão, há poucas variações entre as diversas cidades e ao longo dos anos. Naturalmente, mesmo verificando que entre as mães que usam a creche as trabalhadoras estão muito mais presentes em número e porcentagem, por toda a parte registramos um número consistente de não-trabalhadoras (entre 14 e $22 \%$ nos diversos levantamentos), que não corresponde absolutamente ao número de casos de desamparo social acolhidos nas creches. Em todo o lugar, as trabalhadoras registradas constituem aproximadamente dois terços das mães trabalhadoras, tal como é na população correspondente. Musatti (1992) apresenta uma análise da região Emilia-Romagna, onde as crianças que ingressam na creche alcançam uma porcentagem elevada: $19 \%$ das crianças abaixo dos 3 anos. Essa análise tem examinado a probabilidade da escolha da creche em relação a outras formas de cuidado privado (avó ou baby-sitter) pelas diversas categorias de mães trabalhadoras e indica que a escolha da creche é mais provável entre as trabalhadoras registradas (empregadas e operárias de fábrica em particular), plausivelmente, porque essa escolha combina particularmente bem com o horário continuado dessas mães.

Em síntese, podemos concluir que não parece haver privilégios de categorias particulares de mães no acesso à creche, preenchendo assim um dos critérios de qualidade do serviço educativo apontados pelo documento do Child Care Network da European Commission (Balaguer, Mestres \& Penn, 1992). A creche é uma instituição educativa reivindicada e de fato 
utilizada pelas famílias de diferentes condições socioeconômicas, mesmo que predominantemente pelas famílias em que ambos os pais trabalham.

Uma consideração ulterior é que os dois resultados, que algumas mães não-trabalhadoras recorrem à creche e que a maioria das mães que usam a creche é mais instruída do que a média da população correspondente, trazem uma riqueza de implicações. Ao examinarmos as motivações da escolha da creche por parte das mães encontramos no decorrer dos anos as respostas que atribuem à freqüência das crianças na creche um valor educativo para o seu desenvolvimento social e psicológico em detrimento das motivações de tipo organizativo (Sabbadini, 1999). Não é por caso que essas motivações são mais freqüentes entre as não-trabalhadoras que usam a creche e entre as mães mais instruídas (Musatti, 1992).

Um outro elemento muito interessante que emerge das pesquisas mais recentes (Musatti \& Pasquale, 2001; Dipartimento della Funzione Pubblica, 1997) é o alto grau de satisfação manifestado pelos pais em relação à experiência da creche da parte das suas crianças, grau de satisfação que é também maior do que aquele manifestado por mães que optaram por outras formas privadas de cuidado da criança. Também esse substancial consenso dos pais em relação à creche como instituição educativa que responde a necessidades mais amplas que um simples cuidado deve ser entendido na evolução da experiência da paternidade/maternidade.

\section{0 cuidado das crianças abaixo dos 3 anos: quando não é possível ou desejado ingressar na creche}

A existência das creches como instituição pública educativa, potencialmente acessível a todos as crianças, suscitou, como já dito, uma série de expectativas nas famílias, que tem ultrapassado a capacidade das creches a elas responderem. Vimos que, embora a maioria das mães que utilizam a creche trabalhem, apenas uma certa porcentagem de mães trabalhadoras conseguem uma vaga na creche. Vimos também que as famílias que se servem da creche declaram que o fazem não apenas para resolver o problema da guarda da criança durante o tempo de trabalho dos pais, mas também por uma exigência educativa. Essas considerações trazem algumas interrogações social e pedagogicamente relevantes, com base nas quais foram realizados estudos e experimentadas práticas inovadoras.

Algumas questões se referem à organização das famílias em relação ao cuidado da criança. Quando uma creche, ou seja, a única forma regulamentada de cuidado, não está disponível ou não é desejada, como fazem as mães que trabalham? Quais são as suas escolhas para o cuidado da criança e quais os fatores que determinam essas escolhas?

Um outro conjunto de questões diz respeito à qualidade da experiência da criança e dos pais em casa e às suas necessidades de apoio psicológico e social. Quando uma mãe não trabalha e cria a sua própria criança em tempo integral, como é a sua vida cotidiana? Quais necessidades de apoio social sente? Quando as crianças vivem exclusivamente dentro da família e em casa, quais são suas experiências sociais e cognitivas?

Algumas respostas a essas perguntas saem de uma das pesquisas acima citadas que tem examinado também as soluções de cuidado e a qualidade de vida das crianças abaixo dos 3 anos que não usavam a creche em 10 regiões da Itália Centro-Norte (Musatti, 1992). Dessa investigação, resultou que apenas $18 \%$ das mães trabalhadoras tinham acesso à creche. Além da creche, não havendo outras formas de creches domiciliares (que até hoje existem na Itália só de forma experimental) foram encontradas apenas soluções privadas de cuidado na casa da criança. Estas se dividem entre soluções gratuitas no interior da família (mãe, avó ou outro parente) e ajuda remunerada de uma pessoa que toma conta da criança em casa, por exemplo a baby-sitter. As escolhas para o cuidado com a criança diferem conforme a situação de trabalho das mães.

Verificamos que a solução mais utilizada das mães trabalhadoras (38\%) é a de deixar a própria criança aos cuidados de uma das avós, durante o período de trabalho. A ajuda das avós é um recurso utilizado por todas as categorias de mães trabalhadoras, mas pode- 
se perceber que é praticada de maneira mais relevante pelas trabalhadoras registradas de baixa qualificação. Essas categorias são as que mais recorrem a outros parentes, solução que na verdade é bastante rara. Tem sido constatado, também, que um consistente grupo de mães trabalhadoras, $23 \%$, consegue realizar o milagre cotidiano de conciliar ao mesmo tempo o cuidado da criança e a atividade de trabalho. Um difícil equilíbrio, este, que é alcançado apenas pelas trabalhadoras autônomas, como as lojistas, artesãs e, em menor grau, as profissionais liberais.

Apenas 13,2\% das mães trabalhadoras, e mais freqüentemente nas grandes cidades, deixam a criança com uma baby-sitter. As porcentagens dessa escolha crescem, no entanto, linearmente com o aumento da qualificação do trabalho formal ou não. Raramente acontece com operárias, artesãs e lojistas, mas freqüentemente com trabalhadoras de baixo e médio nível e principalmente com as executivas e as profissionais liberais.

As motivações manifestadas pelos pais indicam com precisão a escolha feita: dizem que "é melhor um familiar", quando uma criança é criada pela avó ou pela própria mãe, que "não confiamos na creche", se escolhem uma baby-sitter, que é uma solução extrafamiliar, mesmo se a pessoa vem até a casa. Mas as análises estatísticas realizadas sobre esses dados tem demonstrado que o elemento determinante da escolha das mães é a sua posição no trabalho, na qual motivações econômicas e grau de flexibilidade do trabalho convergem para determinar essa escolha. Quando a renda do trabalho é baixa e não é possível combinar trabalho e cuidado em tempo integral da criança, a única alternativa - deixar a criança com avós, tios etc. - é o recurso à rede familiar alargada. Para quem ganha mais, tendo uma condição de trabalho mais gratificante e consolidada, recorrer a uma forma de cuidado privado e com custos elevados constitui outra solução possível. A análise da condição socioeconômica do pai tem indicado que embora as condições socioeconômicas do pai e da mãe sejam mais ou menos homogêneas e as mesmas categorias de pais e mães mostrem a preferência para iguais soluções de cuidado, principalmente o aspecto econômico, e não o grau de flexibilidade organizativa do trabalho do pai, influencia a escolha de cuidado da criança.

Embora, à luz desses dados, apareçam claramente as razões materiais que podem estar na base da crescente demanda de creche por parte das mães trabalhadoras, seria um erro pensar que juntamente com essas motivações não existam considerações que emergem de situações relacionais e necessidades psicológicas nas quais hoje os pais de crianças pequenas vivem.

A maioria das mães que não trabalham cuidam da sua criança em tempo integral (Musatti, 1992). Diversas pesquisas apontam que as mães não-trabalhadoras partilham menos o cuidado da criança e que também o apoio oferecido pelos avós é raro (Musatti \& D'Amico, 1996; Musatti \& Pasquale, 2001; Sabbadini, 1999). Sabe-se também que a jornada da mãe em tempo integral é caracterizada por grande solidão ao lado da criança e que durante essa jornada a mãe não-trabalhadora encontra dificuldades para conciliar os trabalhos domésticos e a criação da criança, não se dedica freqüentemente a brincadeiras com a criança e gasta mais tempo que outras mães em frente à televisão (Galardini, Giovannini \& Musatti, 1993; Musatti, 1992; Picchio \& Musatti, 2001). Em geral, a mãe em tempo integral chega a manifestar uma grande dificuldade para a organização do dia-a-dia com as crianças sem o apoio de uma outra presença adulta.

Vimos como a ajuda no cuidado da criança no interior da grande família é oferecida, sobretudo, pelas avós. Também na criação conduzida pela avó convergem complexos elementos demográficos, históricos, socioculturais e psicológicos. A verticalização da grande família que ocorreu nas últimas gerações tornou a presença de uma criança pequena mais rara; assim, acabou facilitando os compromissos de cuidado, mas tem complicado os aspectos psicológicos. Em geral, a ajuda é dada pela avó materna, mas também quando a avó paterna é exigida para os cuidados demonstra a mesma dedicação. É interessante observar que, no caso do cuidado da criança pela avó, os componentes históricos e culturais, que em algumas áreas geográficas chegam ainda a determinar laços interge- 
racionais diferentes das linhas materna e paterna de parentesco (por exemplo, nas vizinhanças de casa), parecem ser ofuscadas pelos vínculos psicológicos profundos ligados à responsabilidade da maternidade. De qualquer forma, os elos de solidariedade intergeracional na ajuda dos cuidados da criança da parte dos avós e da avó, em particular, são percebidos de maneira diferente conforme a condição sociocultural da avó. Se, como vimos, as mães trabalhadoras em condição socioeconômica mais baixa são as que mais freqüentemente recorrem à avó para o cuidado da criança durante o tempo de trabalho, verificamos que, independentemente da necessidade da mãe, são as avós em condição sociocultural mais baixa que se comprometem mais no cuidado do netinho e que sentem esse compromisso como um dever (Musatti \& D’Amico, 1996). Esses dados não estão em contradição com o fato de que o envolvimento da avó na criação da criança vem sempre acompanhado de emoções e sentimentos muito intensos (Budini Gattai \& Musatti, 1999); assim, o que acontece é que essa riqueza emocional na relação entre avó e netinho se entrelaça não sem problemas com a preexistente relação entre avó e mãe e com aquela que vem se construindo entre mãe e criança.

Devo, também, sublinhar que as diversas formas de cuidar da criança em casa diferem muito em relação à qualidade da experiência das crianças, como por exemplo pela quantidade de tempo utilizado pelas crianças em interações de brincadeira com um adulto. Acima de tudo, a experiência cotidiana das relações sociais é diferençável. Em todos os casos, seja as crianças passando o dia com a própria mãe, as avós ou a baby-sitter, os adultos com os quais estabelecem relações durante a jornada de trabalho são poucos e afinal apenas com o adulto que toma conta. Mas, também, as ocasiões de contato social com outras crianças da mesma idade são diferençáveis: elas são raras quando a criança é criada exclusivamente pela mãe ou os avós durante muitas horas do dia e mais freqüentes quando por uma baby-sitter, orientada para levá-la a um parquinho todos os dias.

Em suma, fica muito claro que a situação educa- tiva, material e psicológica que se determina quando a criança é cuidada exclusivamente em casa, hoje, entra em contradição com a transformação dos papéis femininos, mas também com as novas concepções das necessidades educacionais das crianças pequenas.

Um primeiro indicador dessa contradição é a difusão entre as famílias de uma nova perspectiva em relação aos programas para a infância. Já vimos como também muitas mães não trabalhadoras solicitam uma vaga na creche para a sua criança com base em considerações educativas. E, se no passado se podia freqüentemente assistir a um conflito tradicional entre avós e pais pela decisão de levar a criança à creche, hoje, se pode afirmar que a disponibilidade de uma creche interage com a disponibilidade das avós em empenharem-se nos cuidados da criança de uma forma mais complexa. De um lado, o uso da creche contrasta sempre com as concepções mais antigas dos elos de solidariedade intergeracional, por outro lado, a extensão e o prolongamento da ocupação também das avós, a idade mais avançada em que se chega a ser avó e um substancial reconhecimento das novas necessidades das crianças, às quais os programas educativos podem responder, fazem aceitar favoravelmente também pelas avós a ajuda oferecida pela creche.

Um outro indicador importante da dificuldade das famílias com crianças pequenas é a sua resposta diante da proposta de novos programas para a infância que foi feita em muitas cidades italianas nos últimos dez anos.

\section{O s novos programas para a pequena infância e as futuras perspectivas}

A criação de novos tipos de programas para a infância aflorou na Itália no âmbito de intervenções e reflexões muito diferentes dos outros países (Mantovani \& Musatti, 1999). Também nesse caso trata-se de bens públicos instituídos e administrados pelos governos locais que, com base na experiência de gestão das creches, conseguiram acolher a nova demanda das famílias e dar novas respostas. 
As primeiras experiências foram realizadas em 1986 pela prefeitura de Milão com o apoio da Fundação Bernard Van Leer e pela prefeitura de Pistóia, mas os novos serviços logo se difundiram nas cidades onde já existiam creches de alta qualidade educativa. Em seguida, em algumas regiões, como Emilia-Romagna, Úmbria e Toscana, a sua difusão foi também apoiada pelas administrações regionais por meio de consistentes programas financeiros; depois, recebeu novo impulso por uma lei nacional, a lei n ${ }^{\circ}$ 285/1997 para a promoção dos direitos da infância e da adolescência. Estima-se que hoje os novos programas correspondam a cerca de 500 unidades, operando estavelmente e regulamentados com muitas normas regionais e municipais. Os novos programas funcionam com igual sucesso em municípios de dimensão muito diferente: cidades médias ou médio-pequenas, pequenos centros urbanos e também áreas metropolitanas, como Turim, Gênova, Milão, Bolonha, Roma e Palermo.

É característica dos novos programas a grande flexibilidade na formulação do modelo organizativo, que pode variar muito em todos os aspectos de funcionamento como nos horários de abertura, mas também nos estruturais como a locação física fixada em edifícios ou locais autônomos, em centros polivalentes com projetos voltados para crianças de outras idades, ou prever a utilização de locais das creches ou das escolas da infância em diferentes horários de abertura. Essa variedade pode ser resumida em duas tipologias funcionais que correspondem a intervenções que sublinham aspectos diversos do mesmo projeto.

Os programas que correspondem à primeira tipologia foram chamados de Centri per Bambini e Genitori e exigem a presença dos pais ou de outros familiares com as crianças, para partilhar momentos de brincadeira, mas também de pura socialização com outras crianças e pais. Acima de tudo, eles são caracterizados pela intenção de oferecer novas experiências em lugares fora dos muros domésticos. Um elemento fundamental da experiência é a interlocução entre os pais favorecendo, portanto, os momentos de encontro entre eles.

Os programas que correspondem à outra tipolo- gia, ao contrário, foram chamados de Spazi ou Centri per Bambini e aceitam a frequiência de grupos de crianças por um certo número de horas, durante as quais os pais podem se afastar ou permanecer, conforme desejem e de acordo com as necessidades psicológicas da criança. Esses serviços visam principalmente oferecer às crianças a oportunidade de experiências cognitivas e sociais em um grupo de crianças e apoiálas no percurso de conquista da autonomia no jogo e nas relações com os outros. A hipótese é que a possibilidade de observar e aceitar essa conquista acione nos pais uma diminuição da tensão decorrente da carga de responsabilidades educativas e a uma melhor atenção às exigências manifestadas pelo(a) próprio(a) filho(a).

Fica evidente que os novos programas podem dar uma resposta às novas exigências familiares de forma mais circunscrita que o serviço da creche, ampliando essa resposta para um número maior de famílias com crianças pequenas. De fato, eles não oferecem resposta às necessidades de guarda da criança. Os programas que se referem a ambas as tipologias visam oferecer a oportunidade de experiências sociais, seja para crianças quanto para pais, combater a solidão cotidiana do par adulto-criança em casa, e oferecer oportunidades de discussão e interlocução sobre a experiência de paternidade/maternidade. Diferente é a filosofia educativa. No primeiro caso o objetivo é envolver diretamente os pais para partilhar aspectos da própria experiência, no outro, é oferecer-lhes a ocasião de considerar o desenvolvimento, as capacidades e as necessidades psicológicas da própria criança com base em uma nova perspectiva.

A resposta dos pais à oferta desses novos programas foi muito positiva, em ambos os casos, como apontam diversos fenômenos. As pesquisas promovidas por governos locais antes da abertura dos novos programas e voltadas a investigar as expectativas das famílias com crianças abaixo dos 3 anos encontraram percentagens muito altas (em torno de 75\%) de expectativas favoráveis à proposta de ambos os novos serviços. Nas situações em que é necessário regular o número de famílias acolhidas, surgiram lis- 
tas de espera pela vaga. Enfim, em muitas situações onde um programa já está em funcionamento e foram feitos levantamentos (Galardini, Giovannini \& Musatti, 1993; Picchio \& Musatti, 1999) para investigar a satisfação dos pais que o freqüentam, foi constatado sempre um alto nível de aprovação não apenas e nem tanto em relação às modalidades de funcionamento, mas antes em relação à sua criação. Os pais declaram: "era o que sonhavam", "se não existisse precisaria inventá-lo", "a minha vida mudou".

O relacionamento com a creche não é apenas de filiação cultural, mas em quase todas as cidades corresponde a vínculos funcionais importantes. Em geral, foram utilizados recursos do sistema de creche já existentes, seja em termos de pessoal e espaço, como em termos de know-how profissional em relação à educação das crianças e às relações com os pais. Nos novos programas trabalham educadores com experiência em creches, os programas são monitorados pelos próprios coordenadores que dirigem as creches, e há freqüentes iniciativas em conjunto de formação em serviço para os educadores.

Em síntese, a análise da experiência italiana sugere algumas considerações gerais muito preciosas sobre as perspectivas dos programas para a infância, seja na Itália, seja como em realidades sociais semelhantes. Em primeiro lugar, fica confirmada a importância de oferecer aos pais de crianças um amplo leque de escolhas de cuidado da criança (Moss \& Melhuish, 1991). Sugere-se a importância de uma oferta pública que torne possível o acesso à creche para todas as famílias, garantindo um suficiente número de unidades e alta qualidade e oferecendo também condições de dar respostas às necessidades psicológicas dos pais na socialização e no apoio para o desenvolvimento do próprio compromisso educativo.

TULLIA MUSATTI é pesquisadora no Instituto de Ciências e Tecnologias do Conhecimento do Conselho Nacional das Pesquisas em Roma, Itália, há mais de trinta anos. Tem realizado muitas pesquisas sobre os processos cognitivos e de socialização das crianças pequenas nos serviços educativos para a infância e sobre a vida cotidiana das crianças em família. Recentemente, acaba de concluir uma pesquisa-ação sobre as necessidades de socialização de pais e crianças na área metropolitana de Roma. $E$ mail:musatti@ip.rm.cnr.it

\section{Referências bibliográficas}

BALAGUER, I., MESTRES, J., PENN, H., (1992). Quality in services for young children. Brussels: Commission of European Communities, Childcare Network.

BARBERI, P., BONDIOLI, P., GALARDINI, A.L., MANTOVANI, S., PERINI, F., (1998). Linee guida per la qualità del servizio asilo nido nella provincia di Trento. Trento: Provincia Autonoma di Trento.

BECCHI, E., BONDIOLI, A., CENTAZZO, R., CIPOLLONE, L., FERRARI, M., (1999). Strumenti e indicatori per valutare il nido. Un percorso di analisi della qualità di un servizio educativo in Umbria. Bergamo: Junior.

BECCHI, E., BONDIOLI, A., CENTAZZO, R., FERRARI, M., GHEDINI, P. (2000). Gli indicatori di qualità della Regione Emilia-Romagna. Bergamo: Junior.

BENEVENUTI, P., CASTEllani, G., CiPOLlONE, L., FALCINELlI, F., FALTERI, P., MUSATTI, T., (2001). Il monitoraggio della qualità dei servizi per l'infanzia e l'adolescenza. Bergamo: Junior.

BERTIN, G., CATARSI, E., FAENZI, G., FORTUNATI, A.L., FRANGILli, S., GALARDINI, A.L., MUSATTI, T., PORCHIA, S., (1998). Manuale per la valutazione della qualità degli asili nido nella Regione Toscana. Bergamo: Junior.

BUDINI GATTAI, F., MUSATTI, T., (1999). Grandmothers' involvement in grandchildren's care: Attitudes, feelings and emotions. Family Relations, n ${ }^{\circ}$ 48, p. 35-42.

CENTRO nazionale di documentazione e analisi per l'infanzia e l'adolescenza, (2002). I servizi per l'infanzia in Italia. Quaderni del Centro nazionale di documentazione e analisi per l'infanzia e l'adolescenza, $\mathrm{n}^{\mathrm{o}} 21$.

DIPARTIMENTO DELLA FUNZIONE PUBBLICA, (1997). Riorganizzazione e potenziamento dei servizi per la prima infanzia nel Comune di Roma. Roma.

GALARDINI, A.L., GIOVANNINI, D., MUSATTI, T., (1993). Area Bambini. I nuovi servizi per l'infanzia a Pistoia. Bambini, $\mathrm{n}^{\mathrm{o}} 9$, p. 1-32. 
INGROSSO, M., (1988). Stelle di mare e fiocchi di neve. Le famiglie di fronte all'evento nido. Un'indagine in EmiliaRomagna. Firenze: La Nuova Italia.

MANTOVANI, S., MUSATTI, T., (1996). New educational provision for young children in Italy. European Journal of Psychology of Education, XI, p. 119-128.

MANTOVANI, S., RESTUCCIA SAITTA, L., BOVE, C., (2000). Attaccamento e inserimento. Stili e Storie delle relazioni al nido. Milano: Franco Angeli.

MOSS, P., MELHUISH, E. C., (1991). Current and future issues in policy and research. In: MELHUISH, E.C., MOSS, P. (orgs.). Day care for young children. Nova York: Routledge, p. 199-215.

MUSATTI, T., (1992). La giornata del mio bambino. Madri, lavoro e cura dei più piccoli nella vita quotidiana. Bologna: Il Mulino.

MUSATTI, T., ANDREOLI, S., BRAGA, M.P., MAYER, S., (1999). La gestione dei servizi educativi comunali per l'infanzia e le figure dei coordinatori. Roma: Istituto di Psicologia, C.N.R.

MUSATTI, T., D’AMICO, R., (1996). Nonne e nipotini: lavoro di cura e solidarietà intergenerazionale. Rassegna Italiana di Sociologia, $\mathrm{n}^{\circ} 37$, p. 559-584.

MUSATTI, T., MANTOVANI, S. (orgs.), (1983). Bambini al nido: gioco, comunicazione e rapporti affettivi. Bergamo: Juvenilia.

MUSATTI, T., PASQUALE, F., (2001). La cura dei bambini piccoli nei comuni di Città di Castello e Gubbio. In: Quaderni del Centro per l'Infanzia e l'Età Evolutiva. Cura dell'infanzia e uso dei servizi nelle famiglie con bambini da 0 e 3 anni. Perugia: Centro per l'infanzia e l'età evolutiva, Regione dell'Umbria, p. 41-101.
ONGARI, B., MOLINA, P., (1995). Il mestiere di educatrice. Bergamo: Junior.

ONGARI, B., SCHADEE, H.M.A., MOLINA, P., (1996). Lavorare al nido: soddisfazione e immagine del lavoro con i bambini nelle educatrici. Ricerche di Psicologia, n 20, p. 7-39. , (1999). Un'analisi strutturale della rappresentazione sociale della professione di educatrice di nido. Età Evolutiva, $\mathrm{n}^{\circ} 63$, p. 73-80.

PICCHIO, M., MUSATTI, T., (2001). A tu per tu con il bambino piccolo: le parole delle madri. Psicologia Clinica dello Sviluppo, $\mathrm{n}^{\circ} 5$, p. 241-260.

SABBADINI, A.L., (1999). Modelli di formazione $e$ organizzazione familiare. Convegno "La famiglia in Italia". Bologna, Marzo.

TRIFILETTI, R., TURI, P., (1983). Immagini, interpretazioni ed attese della famiglia di fronte al nido: una ricerca condotta in Toscana e in Umbria. In: Gruppo Nazionale Permanente di Lavoro e di Studio sugli Asili Nido, Regione Toscana, Comune di Pistoia (orgs.). Il bambino di fronte ad una famiglia e ad una società che cambiano. Bergamo: Juvenilia.

VARIN, D., MOLINA, P., RIPAMONTI, C., (1996). Sensitive periods in the development of attachment and the age of entry into day care. European Journal of Psychology of Education, $\mathrm{n}^{\circ} 11$, p. 215-229.

ZANELLI, P., (1998). La qualità come processo. L'esperienza dei nidi forlivesi. Milano: Angeli.

Recebido em outubro de 2002 Aprovado em fevereiro de 2003 